\title{
Reaching the unreached - IGNOU's interventions in Tihar Central Jail
}

\author{
Kaushalendra Pratap Singh \\ Indira Gandhi National Open University, India
}

\begin{abstract}
According to the late Indian Prime Minister Indira Gandhi, "Education is a liberating force, and in our age it is also a democratising force, cutting across the barriers of caste and class, smoothing out inequalities imposed by birth and other circumstances. "In India, not all are able to avail opportunities for education due to various reasons including accessibility. In this regard, the Indira Gandhi National Open University (IGNOU) provides education to the disadvantaged and unreached learners (some of them living in special circumstances) to build an inclusive knowledge society through inclusive education.

One of the world's largest prisons is the Tihar Central Jail in New Delhi. It has about 12,000 prisoners accommodated in its 10 jails. There are over 530 prisoners enrolled in various programmes from certificate to postgraduate levels with IGNOU. The School of Social Work (SOSW) is facilitating a study centre of IGNOU in this prison. Faculty members, research scholars and students are visiting this Central Jail thrice a week to reach these learners living in special circumstances with educational programmes as well as counselling services through professional social work intervention. The university has also helped several former inmates to find jobs. The School of Social Work is also involved in extending counselling services to the inmates with regards to their personal matters.
\end{abstract}

This paper explores the extent of interventions being made by IGNOU for the inmates in Tihar Central Jail, for their education, emotional support, transformation and rehabilitation after serving their jail term. 


\section{Introduction}

The Indira Gandhi National Open University (IGNOU), which was established by an Act of Parliament in 1985, continuously strives to build an inclusive knowledge society through inclusive education by reaching the unreached. Today, it serves the educational aspirations of over four million students in India and 36 other countries through 21 Schools and a network of 67 regional centres, about 4,000 learner support centres (Tihar Study Centre is one of them) and 67 overseas centres (IGNOU Profile, 2011). The university offers about 490 certificate, diploma, degree and doctoral programmes.

Over the years, IGNOU has lived up to the country's expectations of providing education to the marginalised sections of society. IGNOU, with its diverse programmes, low cost and a wide network, has succeeded in attracting a significant group of learners from among the disadvantaged (unreached). The university is mandated to reach out to the unreached. Special efforts are being made for providing access to education and equity in opportunities to women, Scheduled Castes, Scheduled Tribes, the rural population, remote areas, tribal regions, differently-abled, and the socially and economically weaker sections of society, including prison inmates. Free of cost education is being provided to all jail inmates across the country (IGNOU, n.d.).

In this paper, an attempt is made to explore the extent of IGNOU's interventions in establishing a study centre for Tihar Central Jail inmates who are disadvantaged and unreached learners (some of them living in special circumstances). The role of SOSW-IGNOU in facilitating a study centre in this prison for the education, emotional support, transformation, and rehabilitation of former inmates is also explored.

\section{About Tihar Jail}

Central Jail, Tihar, was set up in 1958 on the land of Tihar Village. In the beginning, only one Central Jail was commissioned with the lodging capacity of more than 1,200 prisoners. The prison population gradually grew and today about 11,000 inmates are lodged here. It is the largest prison complex in Asia. The Tihar prison complex has nine central jails apart from a District Jail at Rohini, which was commissioned in 2004. The prison is maintained as a Correctional Institution. Its main objective is to transform its inmates into normal members of society by providing them with useful skills and education for development. It is meant to improve the inmates' self-esteem and strengthen their desire to improve (Government of NCT of Delhi, n.d.). 


\section{Profile of jail inmates}

The total population of jail inmates as at 30 June 2012 is 11,998 . As Figure 1 shows, among the inmates $72.94 \%$ are under trial, comprising both males $(69.47 \%)$ and females $(3.47 \%)$. About $27 \%$ of inmates are convicts, comprising both males $(26.05 \%)$ and females $(0.96 \%)$.

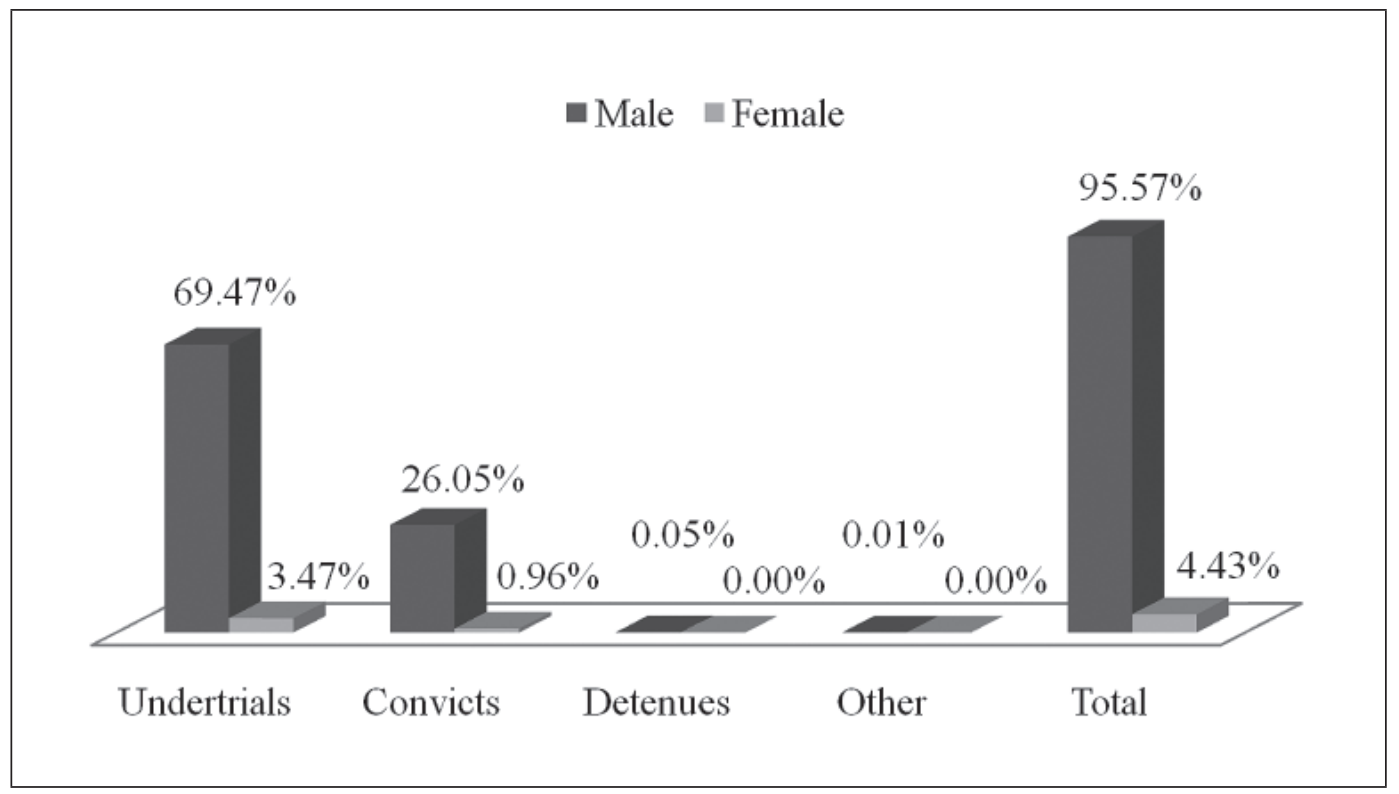

Figure 1 Classification of inmate population as at 30 June 2012 Source: Government of NCT of Delhi

If we look at the profile of jail inmates according to age composition, we find that the age group of $21-30$ years constitutes the highest number, and the age groups of $30-50$ and $18-21$ years constitute the second and third highest numbers, respectively (refer to Figure 2).

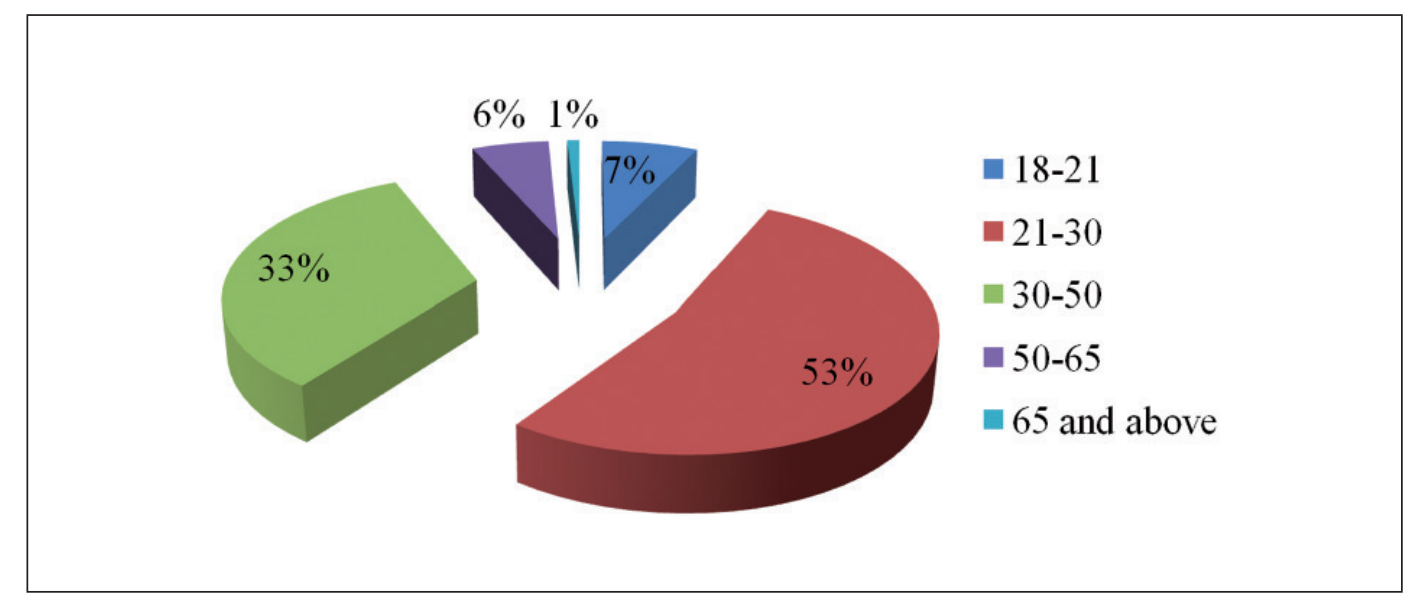

Figure 2 Inmates by age groups 


\section{Reformation}

The Tihar Central Jail is instrumental in providing reformative services to the inmates through various modes such as recreational facilities, educational facilities, panchayat system (local government), and participative management, rehabilitation, legal aid, special courts/lok adalats, creative art therapy, system of parole, system of interviews, ventilation of grievances and societal participation in reformation (Government of NCT of Delhi, n.d.).

\section{IGNOU study centre in Tihar Central Jail}

Before the establishment of the regional centre, Delhi-3, The IGNOU Study Centre in Tihar Central Jail was under the jurisdiction of the Regional Centre, Delhi-1, which was established in 1989. It was a remarkable step taken by the prison administration along with Indira Gandhi National Open University. Both extended their hands to reform and rehabilitate inmates of Tihar Central Jail in the year 1994.

The study centre is certified by the International Organisation for Standardisation (to ISO 9001:2008). A number of inmates use the privileges of the Tihar Study Centre. IGNOU went further by providing free education to prisoners and activated 25 courses such as the Master in Business Administration (MBA), Masters in Social Work (MSW), Bachelor in Social Work (BSW), Master in Tourism Management (MTM) and other valuable programmes. It is a welcome initiative for those inmates who cannot afford the programme fee but are interested in pursuing their education despite being in prison. IGNOU has established around 46 jail study centres in 27 regional centres, and Bhopal regional centre has nine jail study centres (Tihar Study Centre, 2011).

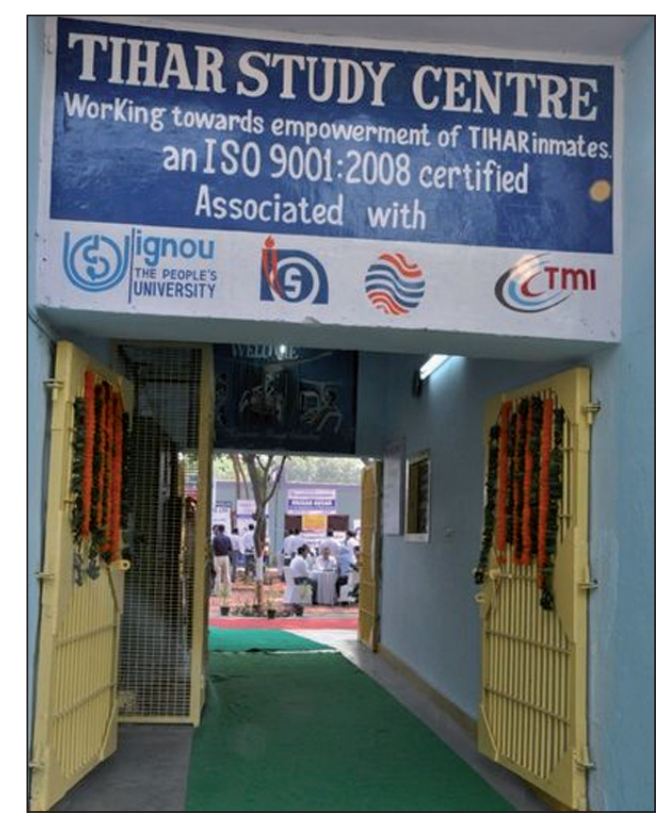

Figure 3 The Tihar Study Centre Source: Photo courtesy of the Tihar Study Centre 


\section{Academic features at the Tihar Study Centre}

Regular counselling sessions are conducted by Internal Academic Counsellors. The centre has two fully furnished classrooms and one computer lab. Internal Academic Counsellors are appointed on merit and as per the eligibility criteria prescribed by the School of Studies. The Tihar Study Centre Library provides additional support to its students with its 7,200 books. Several inmates participate in competitive exams every year (Tihar Study Centre, 2011).

\section{Profile of jail inmate students}

A total of 26 programmes, from certificate to degree level, are being conducted by IGNOU and more than 530 jail inmate students are pursuing various courses at the Tihar Study Centre. Out of the total number of enrolled students, $64 \%$ are pursuing bachelor's degree programmes, $24 \%$ certificate programmes, $8 \%$ master's degree programmes, and $4 \%$ diploma programmes. Among the total enrolled students in master's degree programmes, $40 \%$ are pursuing the Master of Social Work (MSW). In the July 2012 admission cycle, 236 inmates were enrolled in the various programmes of study (refer to Figure 4).

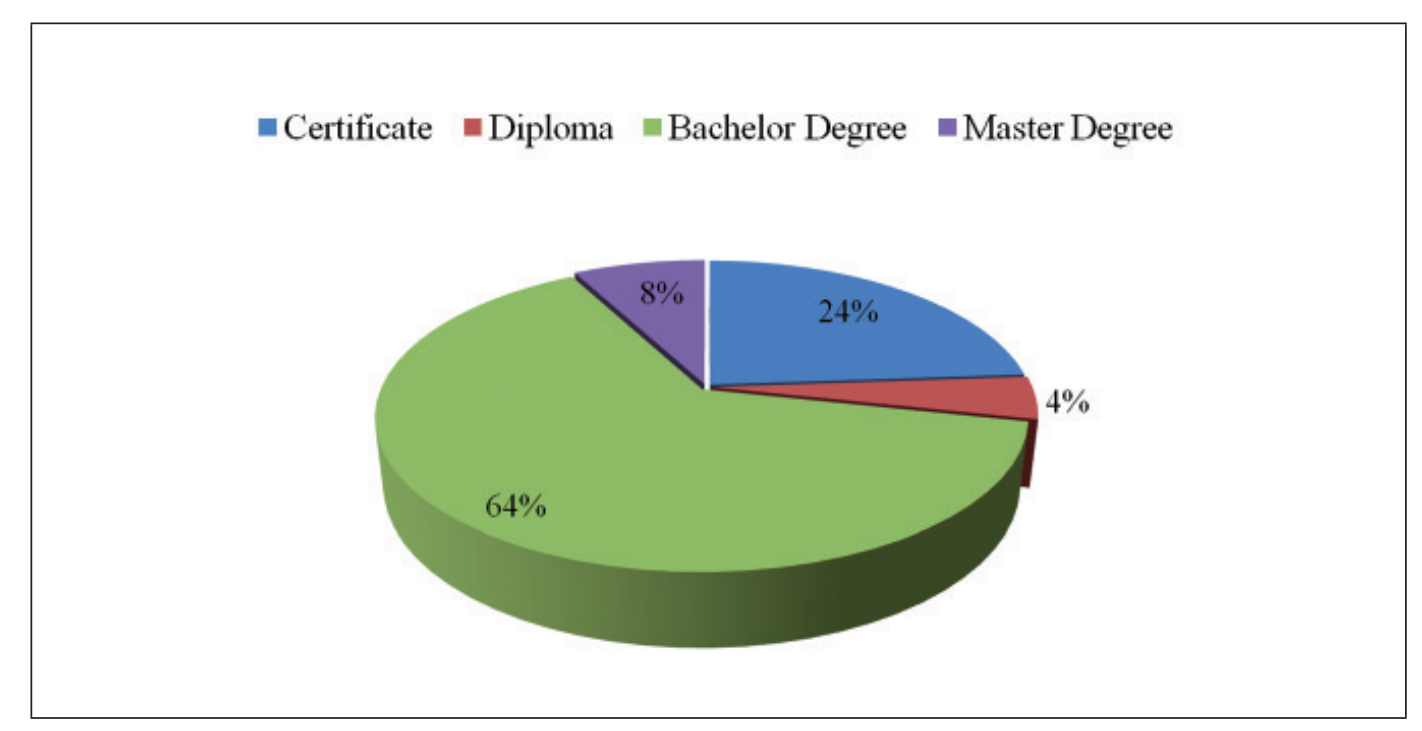

Figure 4 Status of inmate students in the Tihar Study Centre Source: Enrolment list of IGNOU Tihar Study Centre 


\section{The School of Social Work (SOSW)}

The School of Social Work at IGNOU was established in 2007 with the aim of providing quality education in the areas of social work, HIV/AIDS, counselling and family studies by offering programmes leading to the award of certificates, diplomas and degrees.

It is the first School of Social Work to offer social work programmes in ODL and conventional systems. It is also the first School of Social Work in India to take social work education to all the states, including the northeastern states and Union Territories. It has indigenously developed high quality Self-Instructional Material (SIM) and uses the multimedia approach for imparting social work teaching and training through its own (i.e., IGNOU's) TV and radio channels. The school has developed two unique programmes, namely the Master of Social Work Philanthropy (MSWP) and Master of Social Work Counselling (MSWC). MSWP is perhaps the first of its kind across the globe (SOSW, 2011).

\section{IGNOU's intervention: Reaching the unreached}

To provide education to the unreached, particularly to those living in special circumstances, is one of the thrust areas of IGNOU. With this aim, the IGNOU study centre was established in 1994 in Jail No. 3 of Tihar. However, the Study Centre was not active for several years. With the establishment of the School of Social Work, the Study Centre at Tihar Jail was re-activated. The SOSW is facilitating the Regional Centre (Delhi-3) in this regard. Various interventions have been started by IGNOU for the improvement of inmates, such as free education, counselling services, rehabilitation through cultural and recreational programmes, capacity building of inmates, and placement of inmates. The School of Social Work played a vital role in implementing IGNOU's intervention in the Tihar Central Jail by opening the first field work counselling lab at Jail No. 3 .

\section{Activation of the study centre}

The involvement of SOSW has brought many positive outcomes such as the enhancement in the enrolment ratio and a better passing rate. SOSW started its intervention from 2009 onwards. Figure 5 clearly shows that after SOSW's intervention, the graduation rate has increased by almost 15\% compared to 2006-08. Apart from the increased enrolment and successful results, SOSW has tried to make the study centre fully functional through its various programmes. 


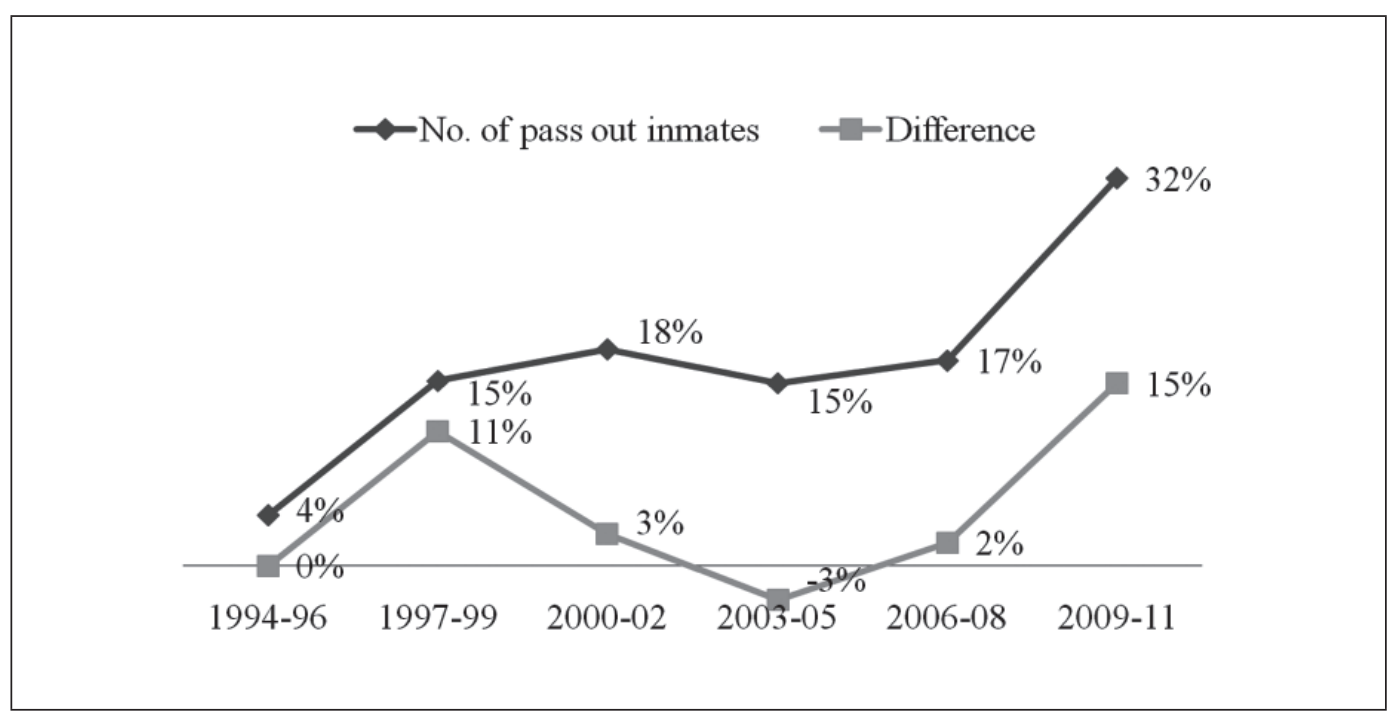

Figure 5 Percentage of students graduating each year Source: Tihar Study Centre

\section{Opening of field practicum labs}

SOSW has opened the first field practicum lab at Jail No. 3 to provide counselling to jail inmates for their rehabilitation and reformation. Subsequently, it was extended to Jail No. 6, which is meant for women. In this jail, the role of the field practicum lab is very important. By seeing the positive outcome of the field practicum labs, the jail authorities have requested SOSW to extend the intervention to all the other nine jails.

\section{Regular visits of faculty, research scholars and students}

To provide psychological and emotional support, and educational inputs, faculty members, research scholars and regular on-campus students undertake close supportive visits thrice in a week to the jail. The faculty members get an opportunity to improve their skills and exposure while research scholars are able to conduct their field practicum for programmes like the Master of Social Work and Bachelor of Social Work. These interventions bring changes in the behaviour of the prisoners. Scholars encourage them to participate in all creative activities so that they can gain their lost confidence.

\section{BSW and MSW programmes}

The BSW and MSW programmes provide inmates with the opportunity for higher studies in professional social work. These programmes are very useful for getting them employment once they are freed. The learners also have the opportunity to help people in need. The speciality 
of these programmes is their practicum components, by which learners experience day-to-day problems in their local surroundings and apply social work methods and techniques to solve these problems. In this regard, the programmes are very effective in correctional settings. Inmates have the opportunity to deal with local problems and to find solutions by their own means. Simultaneously, the programmes also shape the behaviour and conduct of inmates and make them better human beings who can learn from their mistakes and serve society after their jail term. More than 100 inmates have benefitted from these programmes.

\section{Counselling services}

The counselling services are available in all jails. These services are to provide basic knowledge of human relationships; to introduce the learners to biological, psychological and developmental aspects of humans; to help the learners to gain sound knowledge about the what, why and how of counselling services; to improve their psychological well-being through making choices, overcoming psychological blocks and facilitating actions; to make them self- reliant in reaching their desired goals; to provide emotional support; to promote better adaptation of the inmates to their environment and develop their potential; and to assist the inmates in making important personal decisions depending upon the problem, situation and environment.

\section{Job placement}

It has been the constant endeavour of the Tihar Prison Complex to reform and rehabilitate prisoners after their release. In this regard, the study centre has facilitated the job placement of inmate learners.

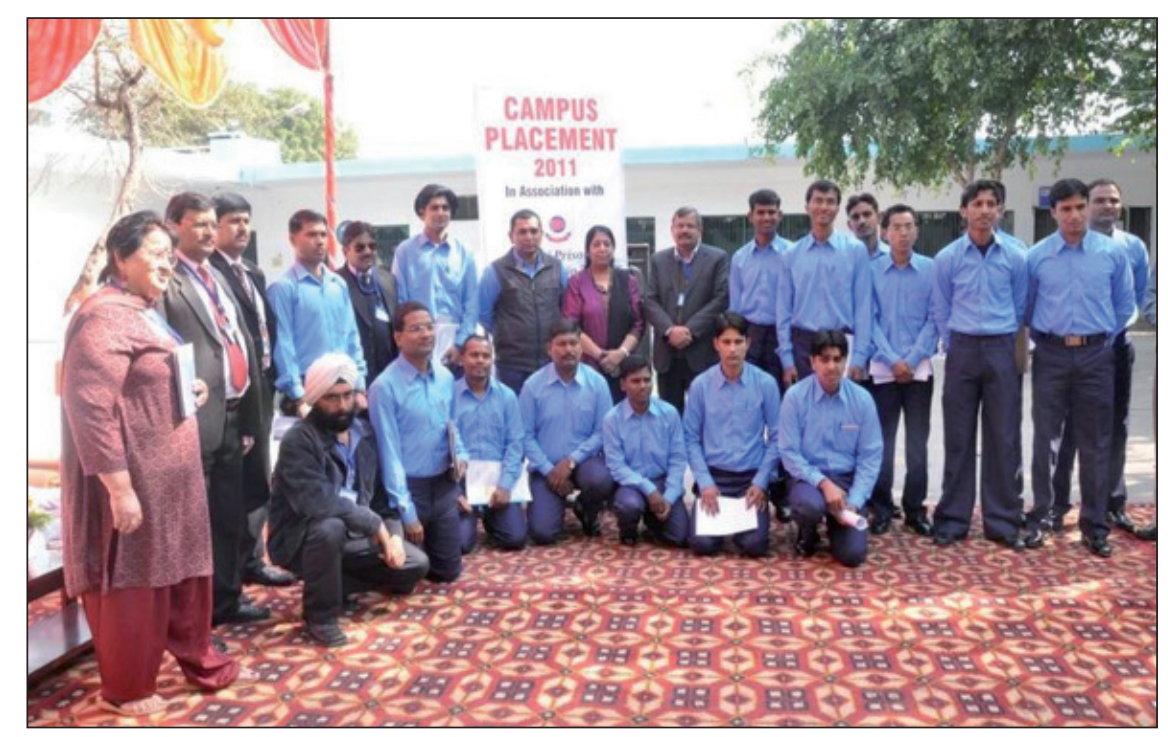

Figure 6 Job placement for former inmates

Source: Photo courtesy of Tihar Central Jail 
The first job placement was organised on 25 February 2011 at the Tihar Study Centre in Central Jail No. 3. In the first round, 45 inmates participated and 15 companies came forward. In the second round, 18 companies showed interest in participating in the programme, of which 15 companies turned up. A total of 74 inmates were selected from 100 inmates. Four inmates got offer letters with a remuneration package of over 6 lakhs (0.6 million) per year.

To date, 357 prisoners have been given job offers by different corporations. A placement cell is being constituted so that these placement drives are conducted at regular intervals and the maximum number of prisoners derives benefit from this reformative and rehabilitative activity.

SOSW is facilitating the process of job placement and making a conscious effort to impart to the inmates the importance of attending job placements by providing counselling and improving their behaviour, conduct and academic credentials. These efforts were reported in all leading newspapers (Tihar Study Centre, 2011).

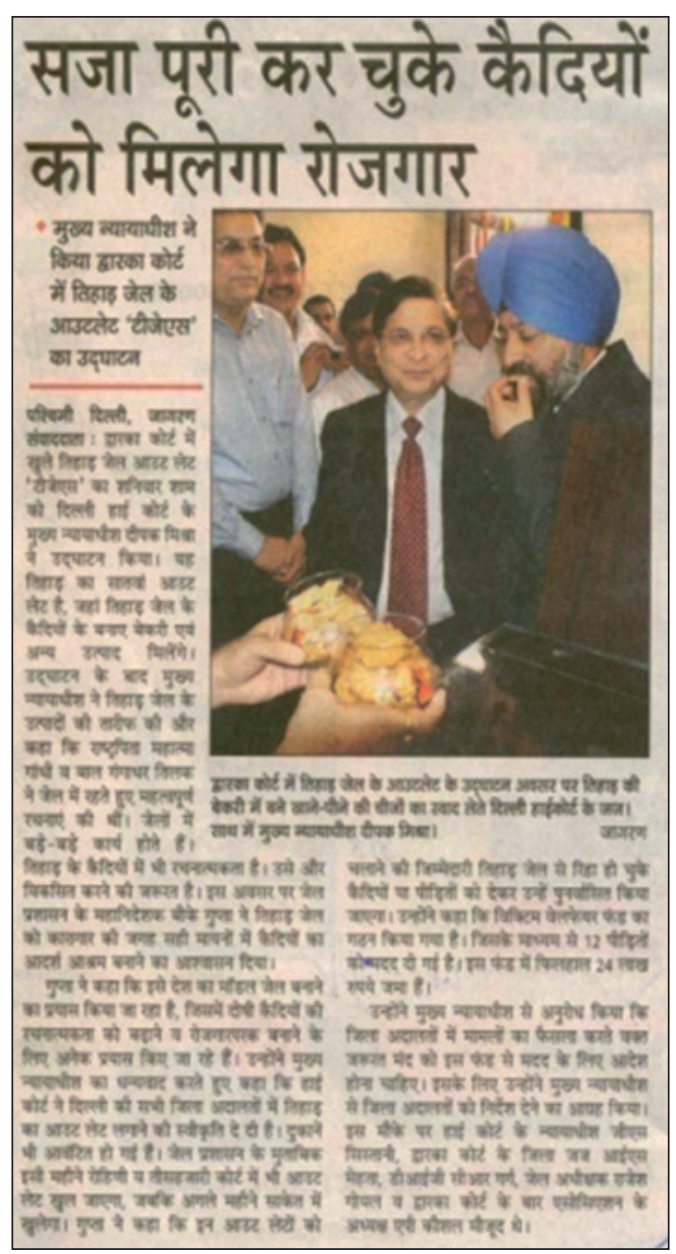

Figure 7 The job placement efforts at Tihar Central Jail Source: Photo courtesy of Tihar Central Jail and Dainik Jagran 


\section{Cultural programmes}

Various cultural programmes are being organised to transform the inmates, who have even formed a music band. They have participated in many competitive events and won prizes. Specially trained mentors often come to Tihar to train them. They organise cultural events in Tihar jail itself. The SOSW facilitates the cultural programmes and invites the School of Visual and Performing Arts to train the inmates. Through the cultural programmes, inmates find relaxation and gain the enthusiasm to change their life in order to find a place for themselves in society.

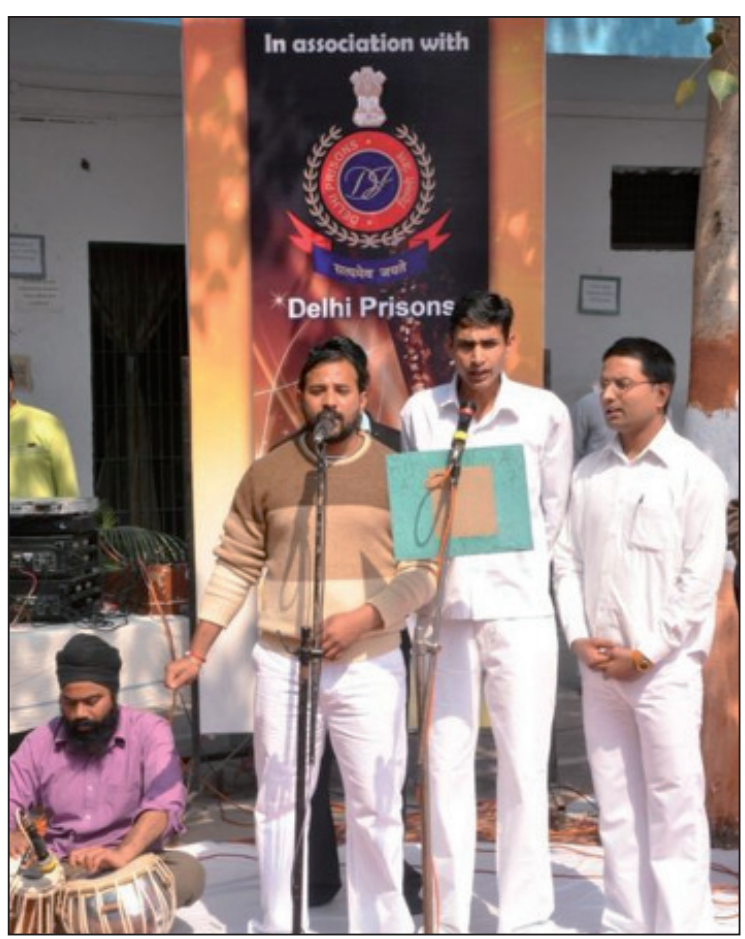

Figure 8 Cultural programme at Tihar Central Jail Courtesy: Tihar Central Jail

\section{Co-curricular activities}

Various co-curricular activities are being facilitated by the SOSW. Recreational activities are carried out regularly in all the jails to channel prisoner energy towards positive causes. Vocational training is the most important component of the correctional activities and its principal objective is to ensure that inmates are imparted skills and attitudes that can facilitate their resettlement in society after release. SOSW is also facilitating health services with the support of inmate students. There is a 150-bed hospital in Central Jail No. 3 and dispensaries in each jail for round-the-clock prisoner health care. The painting activity for jail inmates is one of the best co-curricular activities being facilitated by the SOSW. 


\section{Conclusion}

A flexible and open system of education facilitates the hopes of many learners, especially those who are living in special circumstances such as prison inmates. IGNOU has done commendable work by providing a flexible and open system of education in regard to methods and place of learning, combination of courses, eligibility for enrolment, age for entry, and methods of evaluation. The intervention of IGNOU in Tihar Central Jail is a benchmark for many other jails in India. The facilitation extended by the School of Social Work is phenomenal in terms of changing the lives of inmates through education, emotional and psychological support, recreational programmes, counselling, and close supportive supervision by the faculty, research scholars and regular on-campus students. Job placement is needed for inmates to reshape their life in society and to provide them the opportunity for earning a livelihood after release from imprisonment. Criminals are not born; they are created by the circumstances of society. Through proper reformative services, they are being brought back into the mainstream of society. This has been proven through IGNOU's intervention.

Kaushalendra Pratap Singh (gaur.kpsingh@gmail.com) is with the School of Social Work, Indira Gandhi National Open University, New Delhi, India.

\section{References}

Government of NCT of Delhi (n.d.). Welcome to the Department of Delhi Prisons. Retrieved from http://delhi.gov.in/wps/wcm/connect/Lib_CentralJail/central+jail/home/ on 30 July 2012.

IGNOU (n.d.). About IGNOU. Retrieved from http://www.ignou.ac.in: http://www.ignou. ac.in/ignou/aboutignou/profile/2 on 31 July 2012 .

IGNOU (2011). IGNOU Profile. New Delhi: IGNOU.

IGNOU (2011, March 15). Strengthening HR. Open Letter, pp. 8 -10.

SOSW (2011). Information Brochure of School of Social Work. New Delhi: IGNOU.

Tihar Study Centre (2011). About Tihar Study Centre. Retrieved http://tiharstudycentre. hpage.co.in/index.html on 2 August 2012. 